\title{
The Postoperative Pancreas Imaging
}

\author{
Ahmed Taher ${ }^{1} \quad$ Bilal Mujtaba ${ }^{1} \quad$ Nisha S. Ramani ${ }^{2} \quad$ Asif Patel $^{3} \quad$ Ajaykumar C. Morani ${ }^{1}$ \\ ${ }^{1}$ Department of Diagnostic Radiology, The University of Texas MD \\ Anderson Cancer Center, Houston, Texas, United States \\ 2Department of Anatomic Pathology, The University of Texas MD \\ Anderson Cancer Center, Houston, Texas, United States

\begin{abstract}
Address for correspondence Ajaykumar C. Morani, MD, Department of Radiology, The University of Texas MD Anderson Cancer Center, 1515 Holocombe Boulevard, Houston, TX 77030, United States (e-mail: amorani@mdanderson.org).
\end{abstract}

${ }^{3}$ IGlobal University, Leesburg Pike, Vienna, Virginia, United States

J Gastrointestinal Abdominal Radiol ISGAR 2020;3:87-98

\begin{abstract}
Keywords

- pancreatic cancer

- pancreatectomy

- postoperative complications

- pancreatic fistula

- stricture
\end{abstract}

Recent advances in the surgical techniques and postoperative intensive care have led to a decrease in the mortality rates after major pancreatic procedures, which now ranges from 1 to $3 \%$. However, the morbidity rates are still high, resulting in longer hospital stays and greater cost. Imaging plays a fundamental role in the postoperative assessment. Specially, multidetector computed tomography scans (MDCT) is the modality of choice in the postoperative settings. Early diagnosis of the postoperative complications and differentiating them from being normal or expected postoperative findings is crucial to offer the best possible care for patients and to decrease the morbidity and mortality associated with surgery. In this article, we will briefly review the normal pancreatic anatomy, discuss the main types of pancreatic surgeries, and illustrate the imaging findings during the early postoperative period and of the main postsurgical complications in both acute and chronic postoperative settings.

\section{Introduction}

Recent advances in the surgical techniques and postoperative intensive care have led to a decrease in the mortality rates after major pancreatic procedures, now it ranges from 1 to $3 \%$. However, the morbidity rates are still high, resulting in longer hospital stays and greater cost. ${ }^{1,2}$ Imaging plays a fundamental role in the postoperative assessment. Specially, multidetector computed tomography scans (MDCT) is the modality of choice in the postoperative settings. ${ }^{1,3-5}$ Early diagnosis of the postoperative complications and differentiating them from being normal or expected postoperative findings is crucial to offer the best possible care for patients and to decrease the morbidity and mortality associated with surgery. 6,7

In this article, we will briefly review the normal pancreatic anatomy, discuss the main types of pancreatic surgeries, and illustrate the imaging findings during the early postoperative period and of the main postsurgical complications in both acute and chronic postoperative settings.

\section{Normal Pancreatic Anatomy}

Pancreas is one of the largest digestive glands in the body. In adults, the gland measures 12 to $15 \mathrm{~cm}$ in length and it has a tongue-shape with a soft to firm consistency and lobulated surface.

It is divided into head, neck, body, and tail, thicker at its medial end (head) and thinner toward the lateral end (tail) (-Fig. 1). The head lies within the ' $\mathrm{C}$ ' loop of the duodenum and the remainder of the gland extends transversely and slightly cranially across the retroperitoneum (behind the lesser peritoneal sac and the stomach). The neck is located to the left of the head, immediately ventral to the portal vein $(\mathrm{PV})$. The uncinate process is a triangular prolongation of the caudal part of the pancreatic head behind the superior mesenteric vessels ${ }^{8,9}$ (-Figs. 1 and $\mathbf{2}$ ).

\section{Arterial Supply}

The pancreas has a complex arterial supply via branches from the celiac trunk and superior mesenteric artery (SMA). The pancreatic head and adjacent duodenum are supplied mainly by four arteries: two from the celiac trunk via the gastroduodenal artery (through its anterior and posterior superior pancreaticoduodenal arteries/branches) and two from the SMA via the inferior pancreaticoduodenal artery (through its anterior and posterior inferior pancreaticoduodenal arteries/branches) (-Fig. 2). Multiple 
branches from the splenic artery (including the dorsal pancreatic artery) supply the remainder of the pancreas. ${ }^{8,10}$

\section{Venous Drainage}

Venous drainage of the pancreatic head occurs through the inferior pancreaticoduodenal veins (anterior and posterior)

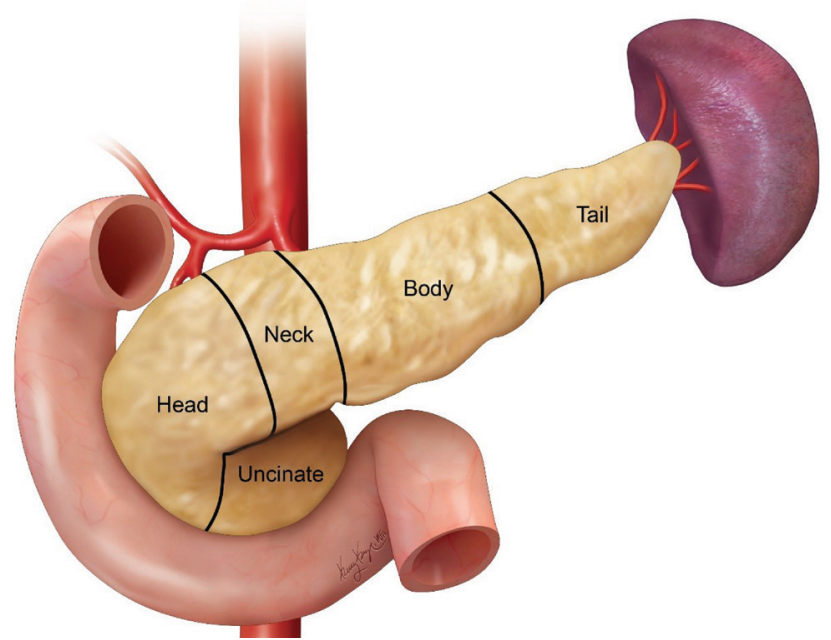

Fig. 1 Illustration of the normal pancreatic anatomy. Pancreas is divided into head, neck, body, and tail. The uncinate process is a triangular prolongation of the caudal part of head behind the superior mesenteric vessels. Image courtesy: Kelly Kage, Media Division, The University of Texas MD Anderson Cancer center. which drain into the superior mesenteric vein (SMV), and through the superior pancreaticoduodenal veins (anterior and posterior) which drain into the PV (posterior) and the gastrocolic trunk (anterior). Venous drainage of the body and tail of the pancreas is more variable but the common pattern is multiple small branches draining into the splenic vein. ${ }^{8,11}$

\section{Surgical Overview and Expected Postsurgical Appearances}

Pancreatic surgery remains the only curative treatment for pancreatic cancer and plays a key role in the management of medically intractable diseases, with most of these procedures divided into resection or drainage. ${ }^{12,13}$ In this review, we will focus on the resection procedures, mainly the different kinds of pancreatectomy as follows.

1. Pancreaticoduodenectomy (PD) or (Whipple procedure $)^{14}$ : It is considered to be the standard procedure and the only curative option for resection of head lesions (most commonly adenocarcinoma), and periampullary neoplasms. This includes en bloc resection of the pancreatic head with uncinate process, duodenum with distal stomach and proximal $20 \mathrm{~cm}$ of jejunum, distal common bile duct, and gall bladder with regional lymphadenectomy. Its variation includes "pylorus preserving pancreaticoduodenectomy." After resection, the

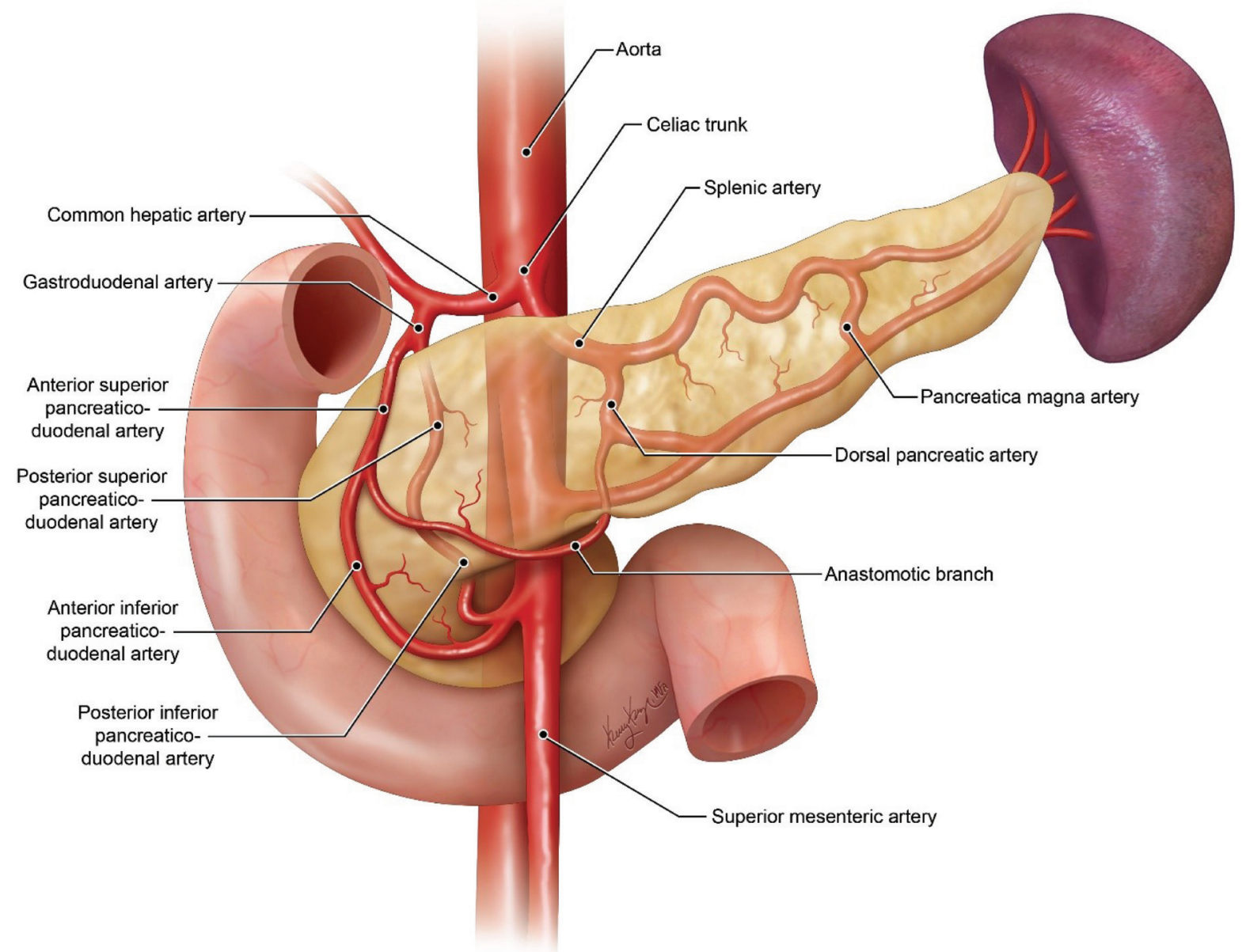

Fig. 2 Illustration of the normal arterial supply to the pancreas. Image courtesy: Kelly Kage, Media Division, The University of Texas MD Anderson Cancer center. 

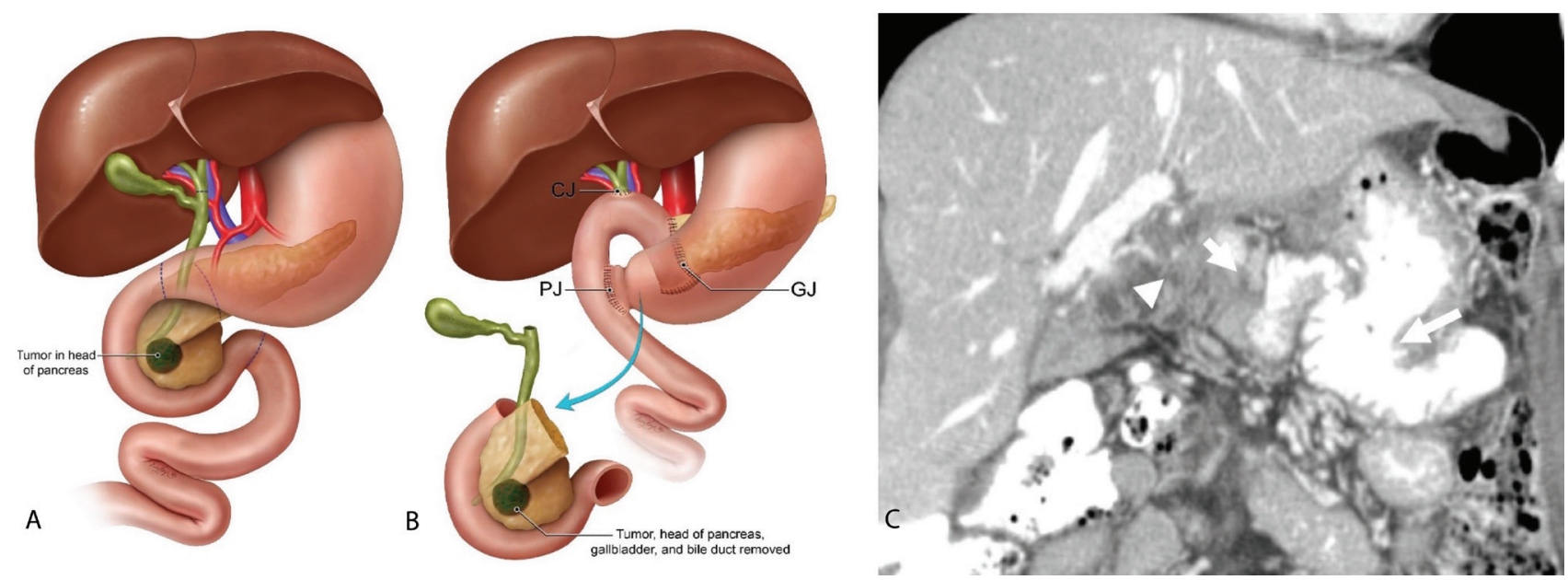

Fig. 3 Diagrammatic illustration for Whipple procedure, showing the preoperative site of a tumor in the head of pancreas (A), then the postoperative anatomical findings with the most common anastomotic sites; pancreaticojejunostomy (PJ), gastrojejunostomy (GJ), and choledochojejunostomy (C) (B). Postsurgical coronal contrast-enhanced CT (CECT) (C) following Whipple surgery in a 60-year-old female for the pancreatic head cancer shows gastrojejunostomy (long arrow), pancreaticojejunostomy (short arrow), and choledochojejunostomy (arrowhead), the three classic anastomoses performed as part of the Whipple surgery.

surgeon establishes three anastomoses for reconstruction, namely, the pancreaticojejunostomy (PJ) or pancreaticogastrostomy (PG), hepaticojejunostomy (HJ) or choledochojenostomy (CDJ), and gastrojejunostomy (GJ) (-Fig. 3).

Postoperative anatomy after PD. ${ }^{3}$ It usually varies according to the technique used, but we should mainly focus on the three main anastomotic sites:

- Pancreaticojejunostomy (PJ) or pancreaticogastrostomy (PG): The jejunal loop is most often anastomosed to the right of the pancreatic remnant, anterior to the SMA, and confluence of the SMV, PV, and SV. ${ }^{15,16}$ It is seen as a short blind pouch of jejunum due to the usual end-to-side anastomosis. This is important as it can often be misinterpreted as a fluid collection. Sometimes collapsed loops of the bowel close to PJ can mimic tumor recurrence or hematoma. ${ }^{4}$

In cases with PG, the pancreas is anastomosed to posterior wall of proximal stomach and can be seen as a defect on MDCT. ${ }^{17}$ Surgeons' preference is always the main factor for choice between those two techniques, as the incidence of overall postoperative complications and the mortality rate are not significantly different between them. However, a recent meta-analysis shows that the incidence of postoperative pancreatic fistula is lower with PG than with PJ. ${ }^{17,18}$

- Hepaticojejunostomy (HJ) or choledochojejunostomy: This one lies at a short distance from the pancreaticojejunostomy (less than $5-10 \mathrm{~cm}$ distally), and is associated with expected pneumobilia. ${ }^{16,17}$

- Gastrojejunostomy (GJ): This anastomosis can be 30 to $40 \mathrm{~cm}$ distal with a segment of the jejunum anastomosed to the stomach (antecolic), or it can be at a short distance from the above two anastomoses. Exact position of this anastomosis may undoubtedly vary depending on the institution and surgeon. ${ }^{16,17}$
- Pylorus-preserving pancreaticoduodenectomy (PPPD), a variant of Whipple procedure that retains the gastric antrum and the first part of duodenum and, anastomosing it to the jejunum creating a duodenojejunostomy (DJ). ${ }^{19}$

2. Distal pancreatectomy (DP): It is performed for distal pancreatic cancers through open procedure or by laparoscopy, depending on the location, size, and involvement of the surroundings. En-bloc splenectomy is usually also done ( $\boldsymbol{- \text { Fig. }} \mathbf{4}$ ) to allow complete resection and avoid local tumor recurrence. . $^{60}$

Normal postoperative anatomy following DP: Unlike the Whipple's procedure, there is usually only minimal disruption of the normal anatomy after DP because the surgeon basically resects the distal pancreas and seals off the remnant with no anastomoses between pancreas and bowel, unless rarely, a PJ to the distal pancreas is done for chronic pancreatitis with proximal obstruction. Multiple studies demonstrate no significant difference in the incidence of postoperative pancreatic fistula formation between PD and DP procedures or between open and laparoscopic DP procedures. ${ }^{21,22}$ Despite the less morbid or less extensive DP surgery compared with PD, some other studies have observed that DP has a higher rate of some complications, especially the pancreatic fistula (PF), abscess, and pseudocysts, which are the most common complications of DP. ${ }^{23}$ These are described in detail next.

3. Central pancreatectomy (CP): It has been proposed as an alternative to both PD and DP for the removal of benign, traumatic and low malignant lesions in the neck or body of the pancreas, to preserve the function of the remaining parenchyma. ${ }^{6,24}$

Normal postoperative anatomy following CP: Surgeons usually close the proximal stump of the remnant pancreas with either a mechanical stapler or manual suture, similar to DP. Then they anastomose the distal stump of 
A
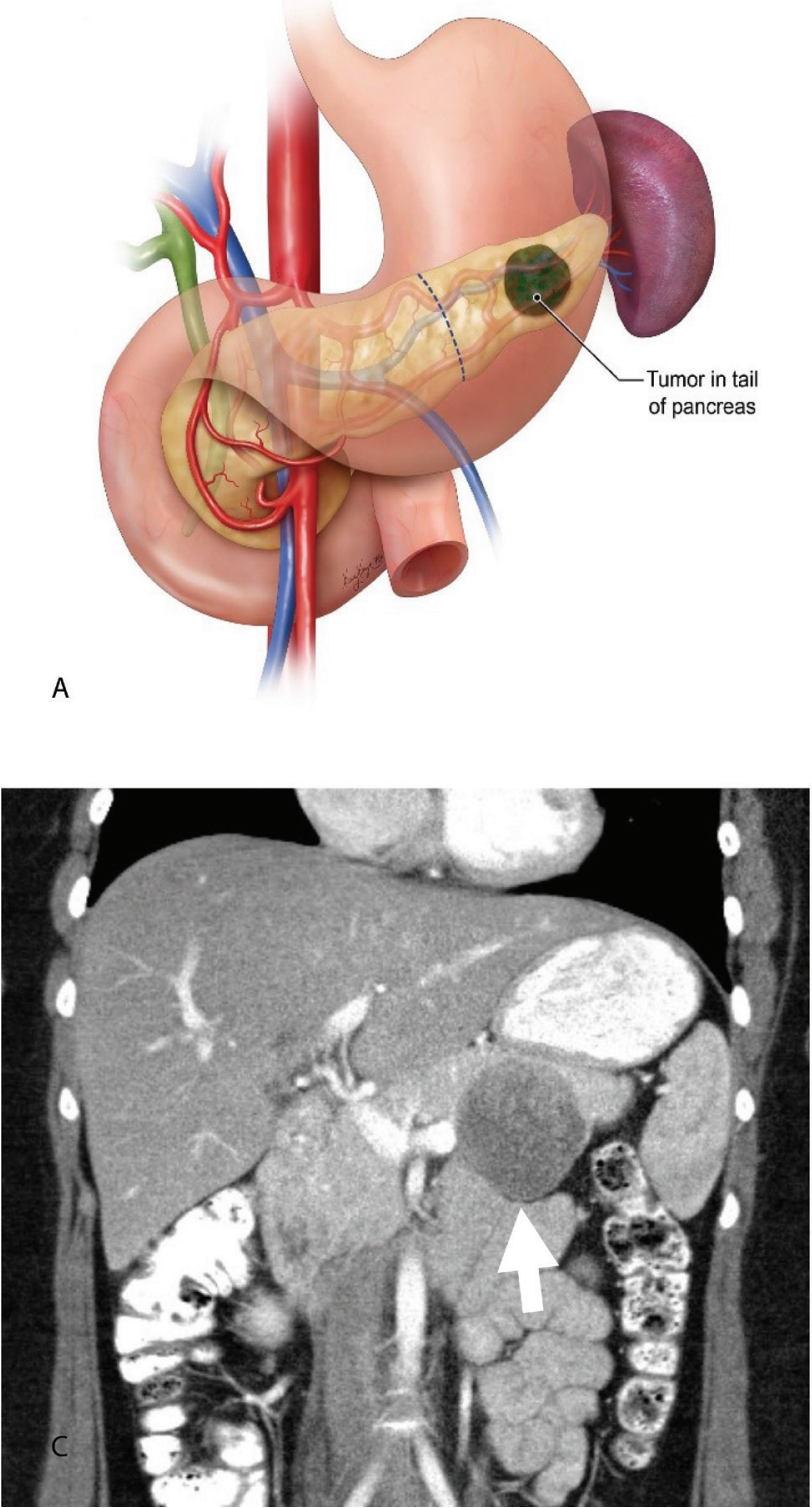

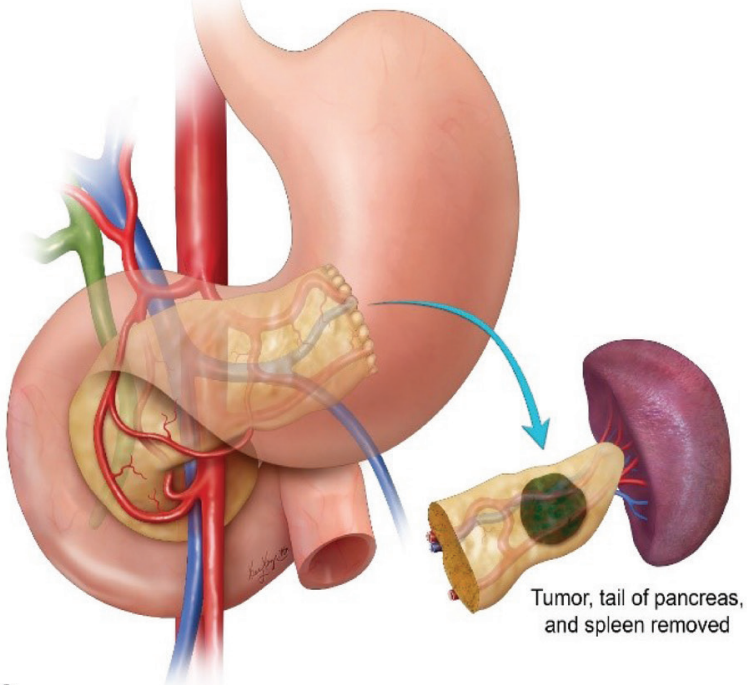

B

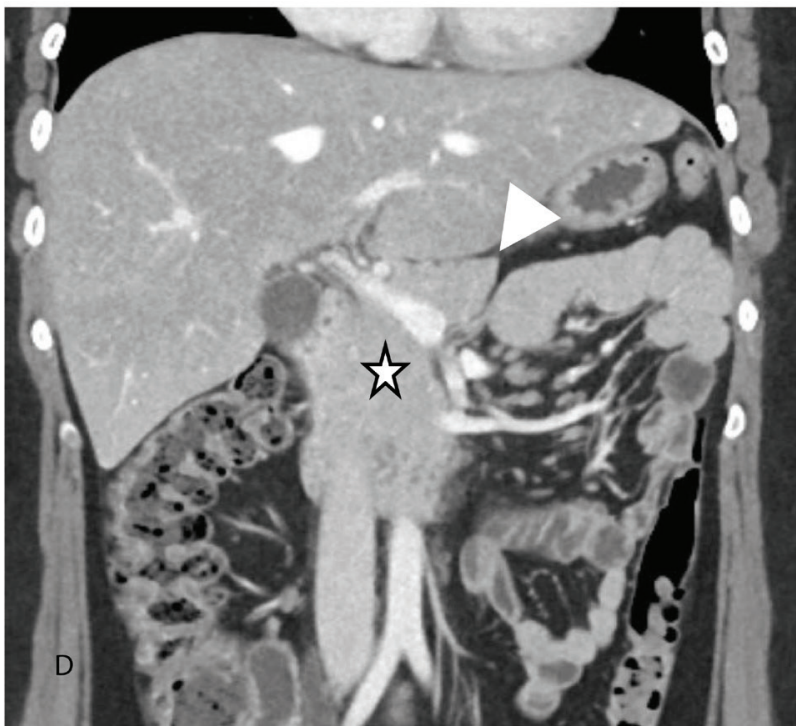

Fig. 4 Diagrammatic illustration for distal pancreatectomy (DP) procedure, showing the preoperative site of a tumor in the tail of pancreas (A), then the postoperative anatomical findings with a splenectomy and a sealed off pancreatic remnant with no anastomosis (B). Coronal postcontrast contrast-enhanced CT (CECT) images shows a circumscribed distal pancreatic mass in a 19-year-old female (C) and postoperative anatomy following subsequent distal pancreatectomy and splenectomy (D). This was proven to be solid pseudopapillary tumor (SPT) of pancreas. Residual unremarkable pancreas (star) is sealed-off along the resection margin (arrow).

the pancreas to the jejunum (PJ), or attach it to the posterior wall of the stomach (GJ) similar to Whipple surgery. Finally, this leads to a Roux-en-Y bowel at the level of the splenomesenteric venous junction, which separates the head of the pancreas from the body and tail ${ }^{25}$ ( - Fig. 5). CP has the advantage of preserving a large portion of normal parenchyma than compared with the two previous surgeries and this may lead to a lower risk of diabetes, in addition to a better residual exocrine function of the pancreas. On the other hand, it has a higher risk of postoperative pancreatic fistula formation because of the two different suture lines. ${ }^{25-27}$
4. Total pancreatectomy (TP): It is also known as a "double Whipple" and is reserved for selected cases with pancreatic diseases involving the whole gland, such as familial pancreatic cancer, metastases, and chronic intractable pancreatitis. The procedure consists of removal of the entire pancreas, spleen, portions of the duodenum, common bile duct, and the gallbladder. ${ }^{28,29}$

Normal postoperative anatomy following TP: It results in two anastomoses-one at the biliary tree (hepaticojejunostomy) and the other at the remaining part of the duodenum (duodenojejunostomy). This procedure leads to a complete pancreatic exocrine and endocrine insufficiency. This also 

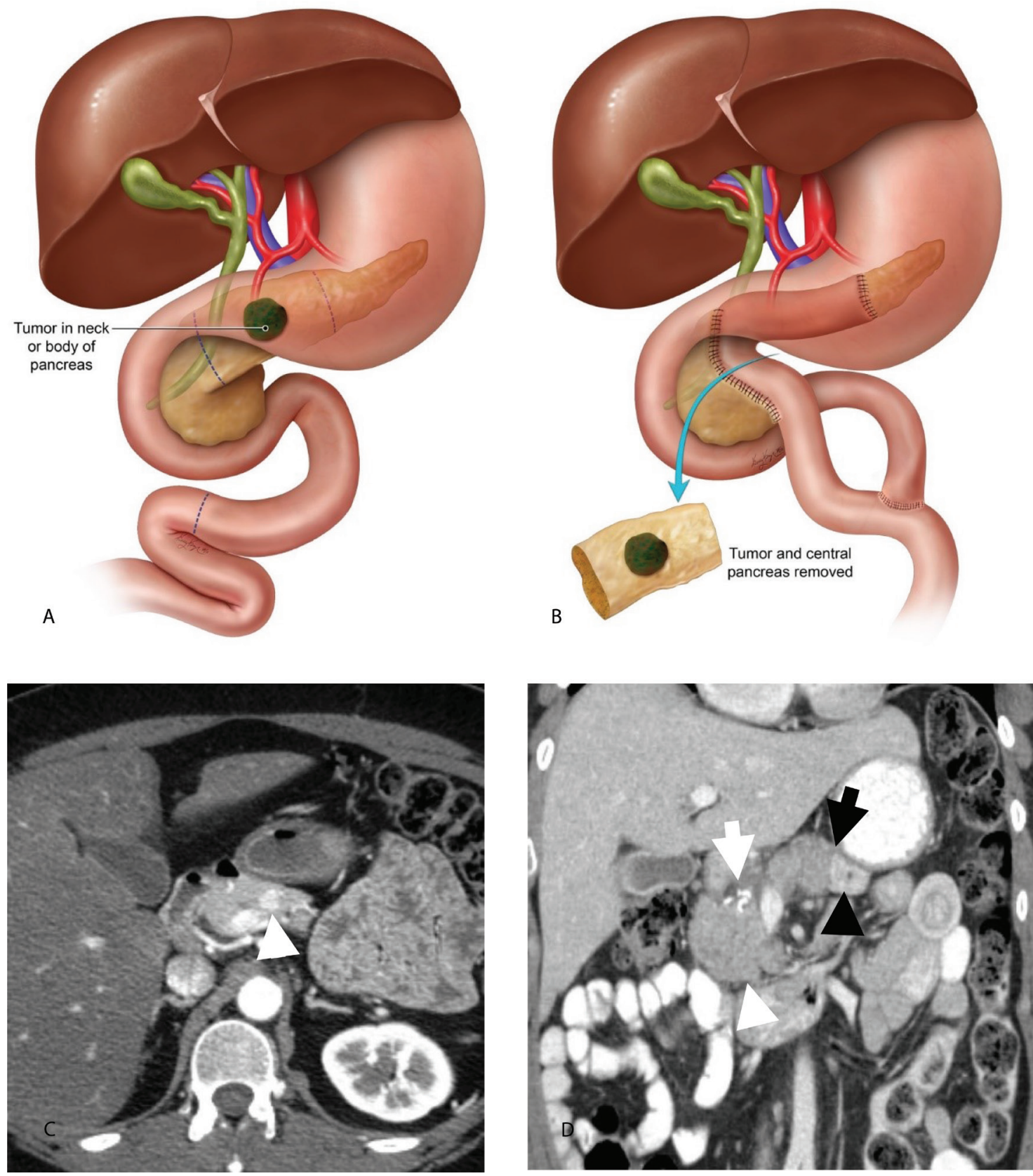

Fig. 5 Diagrammatic illustration for central pancreatectomy (CP) procedure, showing the preoperative site of the tumor in the pancreatic body (A), then the postoperative anatomical findings of central pancreatectomy with pancreaticojejunostomy (B). Axial arterial phase postcontrast CT (C) in a 53-year-old woman performed following persistent abnormal abdominal sensations shows small avidly enhancing mass (arrow) in the proximal pancreatic body. Central pancreatectomy was done for its resection and this was proven to be pancreatic neuroendocrine tumor. Coronal postcontrast CT image (D) shows expected postoperative anatomy with unremarkable pancreatic head (white arrowhead) with adjacent surgical material (white arrow) to seal-off its medial end, and distal pancreatic stump (black arrow head) anastomosed (black arrow) to adjacent jejunum.

carries an extremely high postoperative morbidity and mortality rates, especially if it is secondary to the postoperative complications of a previous resection. ${ }^{30,31}$

\section{Imaging Evaluation}

Although plain radiographs are often performed for initial imaging evaluation in the early postoperative settings after any abdominal surgery, and this is supplemented with ultrasound following hepatopancreatobiliary surgeries, multidetector computed tomography scans (MDCT) is the modality of choice to evaluate postoperative changes and potential complications. Most patients undergo routine follow-up imaging one week after surgery unless immediate complications are not suspected. ${ }^{32}$ MDCT evaluations starts with unenhanced phase before contrast material injection to help detect calcifications and hemorrhage. Then we start with an injection rate of 3 to $4 \mathrm{~mL} / \mathrm{sec}$ of $350 \mathrm{mg} / \mathrm{mL}$ iodinated contrast followed by $20 \mathrm{~mL}$ saline flush. We study it during 3 phases: arterial phase (20-25 seconds post injection), 
pancreatic phase (35-40 seconds), and late venous phase (delay of 70 seconds). The pancreatic phase is crucial in the determination of vascular complications and for maximizing enhancement difference between the tumor and the surrounding parenchyma, and the portal venous phase helps characterize metastases to the liver during peak hepatic enhancement in addition to fluid collections. ${ }^{32-35}$

MRI performance is similar to CT, but it may not be readily available and it requires greater patient compliance. Hence, MRI with MRCP is mainly reserved to assess the pancreaticobiliary ducts and anastomoses. MRI protocol includes multiplanar $\mathrm{T} 1 \mathrm{~W}$ and $\mathrm{T} 2 \mathrm{~W}$ sequences with and without fat saturation, diffusion-weighted imaging, and three-dimensional (3D) MRCP images. Hepatocyte specific contrast is administered for multiphasic postcontrast imaging which includes late scan (often 20-30 minutes) in the biliary excretory phase to evaluate the biliary ducts/leak. ${ }^{35}$

Imaging shows the normal postoperative anatomy with various anastomoses as discussed earlier. Pneumobilia, perivascular soft tissue thickening or cuffing, fluid collections, regional nodal enlargement, edematous swelling at the anastomoses, and peripancreatic or mesenteric fat stranding are the usual expected postsurgical inflammatory changes. ${ }^{35}$ By $\sim 3$ to 6 months, much of the inflammatory changes surrounding the surgical bed usually get resolved, this includes resolution of some of the postoperative complications such as seromas, ascites, abscesses, fat stranding, fistulas, and acute pancreatitis. ${ }^{34}$ Despite the high recurrence risk and poor long-term survival rates, no evidence-based guidelines exist for follow-up timing in cancer cases. Based on expert opinion, current guidelines from the National Comprehensive Cancer Network (NCCN) and the European Society of Medical Oncology (ESMO), recommend CT imaging every 3 to 6 months for 2 years, then once per year afterward. ${ }^{36}$

\section{Postoperative Complications}

The most common postoperative complications following pancreatic surgery includes ascites, seroma, abscess, anastomotic

Table 1 Potential immediate and delayed complications of pancreatic surgery on imaging

\begin{tabular}{|l|l|}
\hline Early & Delayed \\
\hline Ascites & Anastomotic stricture \\
\hline Seroma & Adhesions \\
\hline Abscess & Pancreatitis \\
\hline Anastomotic leak & Local tumor recurrence \\
\hline Hemorrhage & \\
\hline Pancreatic fistula & \\
\hline $\begin{array}{l}\text { Portomesenteric venous } \\
\text { thrombosis }\end{array}$ & \\
\hline Pancreatitis & \\
\hline Delayed gastric emptying & \\
\hline Adhesions & \\
\hline Hepatic infarct & \\
\hline
\end{tabular}
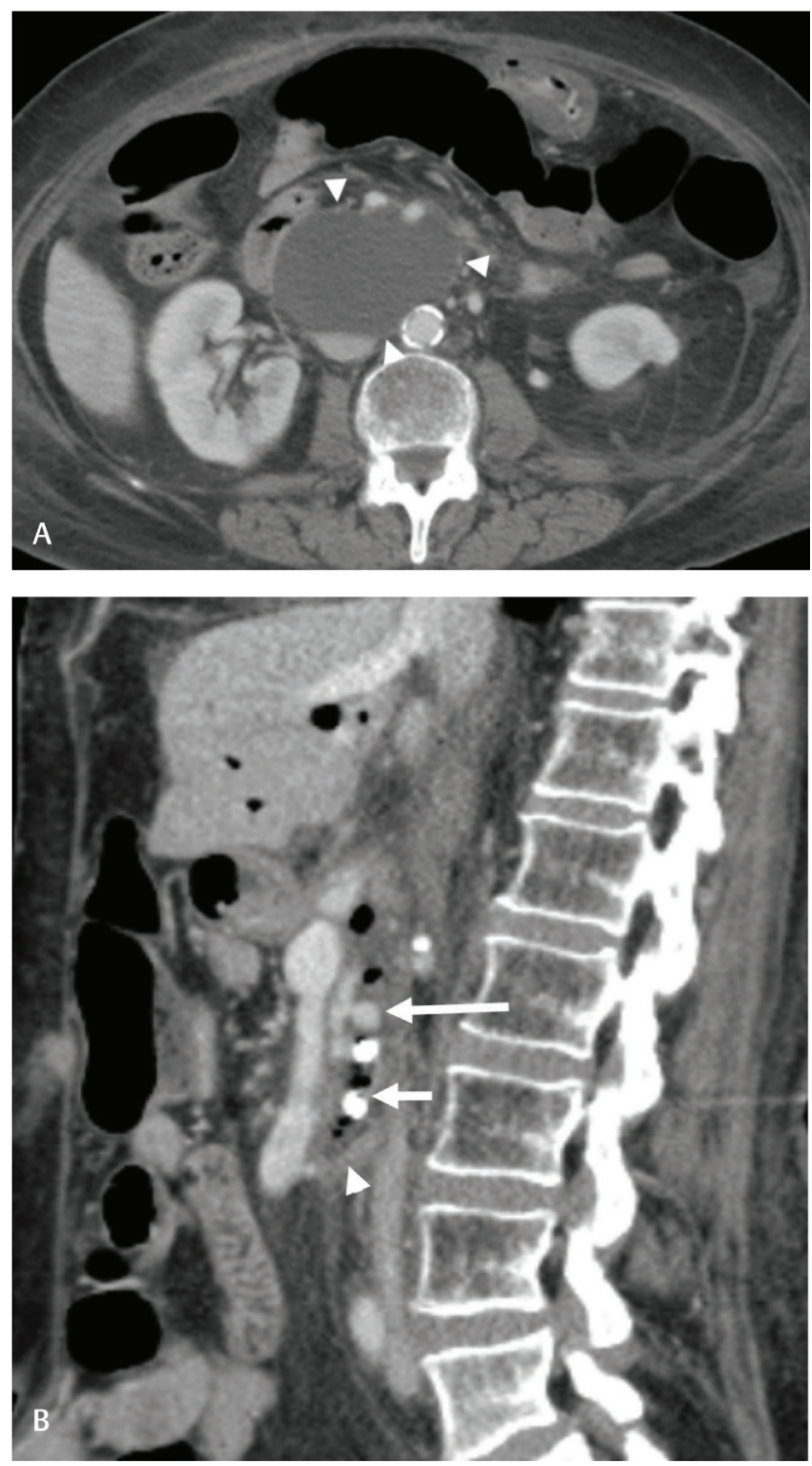

Fig. 6 (A, B) A 77-year-old woman who was status post Whipple surgery for pancreatic head cancer. Patient presented with right flank pain and fever 2 weeks after surgery. Axial contrast-enhanced CT (CECT) (A) showed rim enhancing fluid collection in the surgical bed suspicious for complicated fluid collection. This was proven to be abscess following drainage catheter placement. After 6 further weeks, patient presented with bloody drainage from this catheter. Sagittal CECT (B) shows a subcentimeter saccular pseudoaneurysm involving the superior mesenteric artery (long arrow) within the abscess cavity, which is seen as thick rim-enhancing collection (arrowhead) with drainage catheter (short arrow) within.

leak, hemorrhage, pancreatitis, pancreatic fistula, delayed gastric emptying, portomesenteric venous thrombosis, and anstomotic strictures. Postoperative complications may be categorized into early and delayed categories based on the time after surgery (-Table $\mathbf{1}$ ).

1. Seroma, ascites, and abscess: After Whipple procedure, around $100 \%$ of patients get varying amounts of fluid collection in or around the surgical bed, along the surgical tract, and in the abdominal wall and retroperitoneum. Radiological and clinical findings together are the key to tell apart seroma from abscess, leakage, or 


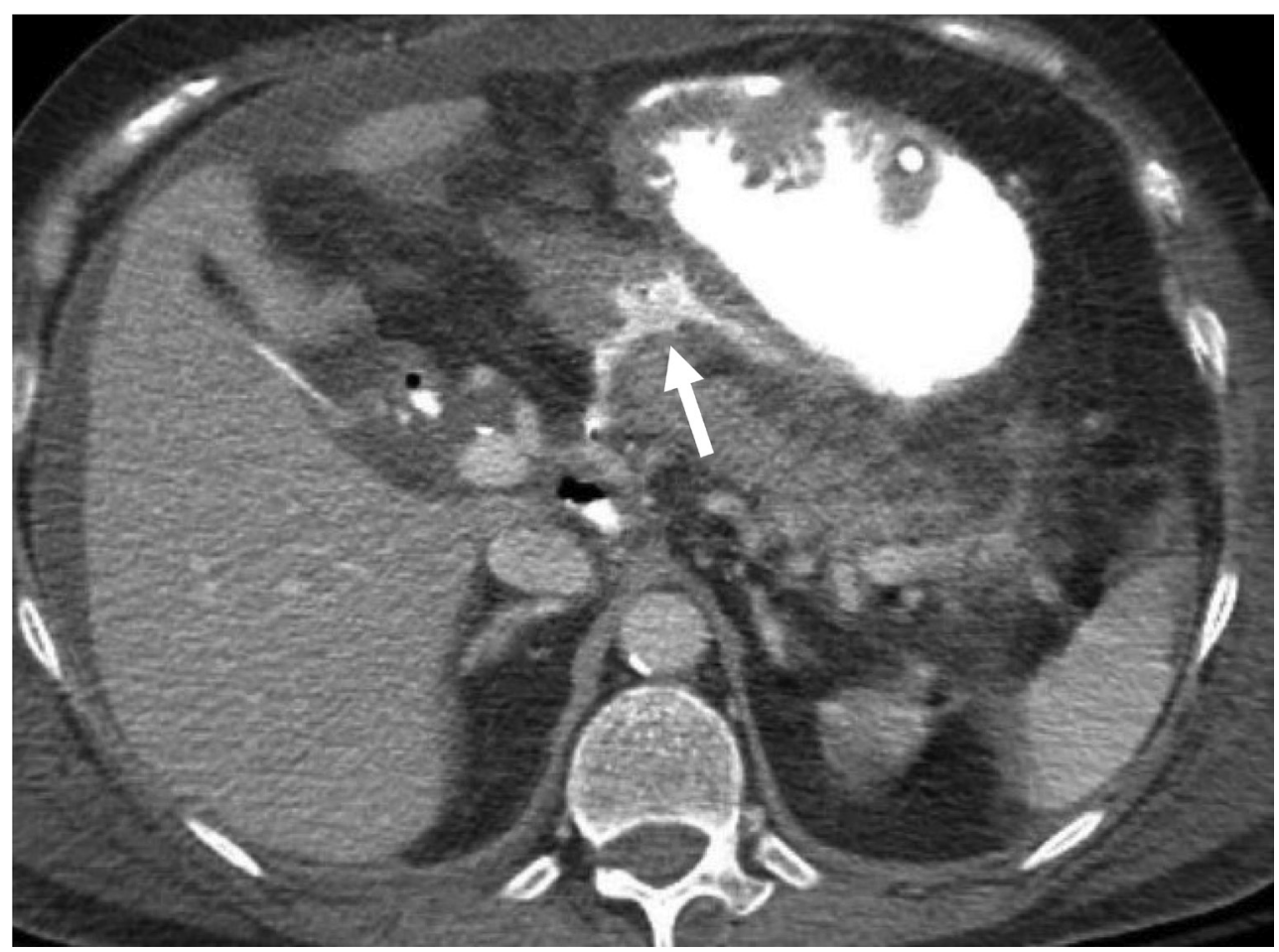

Fig. 7 An 81-year-old man who was status post Whipple surgery for ampullary carcinoma with increasing drain output. Axial contrast-enhanced CT (CECT) with intravenous and bowel contrast, shows extraluminal bowel contrast in the surgical bed suspicious for the leak (arrow) from the gastrojejunostomy or pancreaticojejunostomy site.

hemorrhage. ${ }^{4,37}$ Seromas present as simple fluid collections without enhancing rim which is often seen with abscesses or complicated fluid collections ( - Fig. 6). The incidence of intra-abdominal abscess after PD surgery is around $6 \%{ }^{37}$ Hemorrhage presents with high attenuating collections, and is described in detail below.

2. Anastomotic leakage: Anastomotic leakage is seen in 4 to $10 \%$ of cases following PD. ${ }^{38}$ On cross-sectional imaging, leakage may appear as fluid collections in or adjacent to the surgical bed ( - Fig. 7 ), in perihepatic region, and may spread into the peritoneal cavity. If biliary leakage is suspected clinically, a hepatobiliary iminodiacetic acid (HIDA) scan is one of the best tools to detect approximate location and size of the leakage. ${ }^{39}$

3. Hemorrhage: Hemorrhage is suspected when the serum hemoglobin level falls below $8 \mathrm{mg} / \mathrm{dL}$ or when patient is hemodynamically unstable and/or need intravenous fluid administration or blood transfusion. ${ }^{40}$ Hemorrhage presents with high attenuating collections on CT. CT angiogram (CTA) may be needed in these cases to locate the site of bleeding and to rule out postsurgical arterial pseudoaneurysms. Tc-99m RBC scan may be needed to detect the intermittent or minimum bleeding not detected on CT, as it is the most sensitive imaging modality for detection of GI bleeding $\left(0.1 \mathrm{~mL} / \mathrm{min}\right.$ threshold rate). ${ }^{41}$ But on the other hand, surgical intervention should not be based on only a Tc-99m RBC scan, because it has a poor anatomic localization of the bleeding site and it cannot determine the pathological cause of bleeding. ${ }^{41}$ Conventional angiography is an important tool in detecting as well as a therapeutic modality for these pseudoaneurysms. Thus, it has an increasingly important role in the diagnosis and management of acute gastrointestinal hemorrhage that is secondary to pancreatitis or a pancreatic surgery, as the culprit leaking artery or pseudoaneurysm may be embolized/coiled in the same sitting to stop the bleeding $\left(\right.$-Fig. 8). ${ }^{42}$

Based on the time course, early postoperative hemorrhage occurs within first 24 hours after surgery and often results from active bleeding of the poorly ligated or retracted vessels, for example, from the gastroduodenal artery (GDA) stump. Bleeding typically occurs into the peritoneal or retroperitoneal regions. Late postoperative hemorrhage occurs mainly after 5 days and has a high association (up to 66\%) with anastomotic breakdown and sepsis; it is usually due to vascular erosion or pseudoaneurysm (-Figs. $\mathbf{6}$ and $\mathbf{8}$ ) in the mesenteric vasculature. ${ }^{43}$ This is usually managed with angiography and endovascular approach. ${ }^{42}$

4. Pancreatic fistula: Pancreatic fistula is the single most important cause of morbidity and mortality after Whipple procedure. It occurs due to leakage of amylase rich secretions at the PJ anastomosis site or from direct trauma to the pancreas. ${ }^{44,45}$ In these cases, the surgical drain amylase levels are usually three times higher than the serum levels on the third postoperative day, which is almost always diagnostic. ${ }^{46}$ Although the drain output is the key to diagnosis, CT is very helpful in detecting pancreatic fistulas ( $\mathbf{- F i g . 9}$ 9). Presence of a focal fluid collection or hemorrhage adjacent to the PJ is strongly 

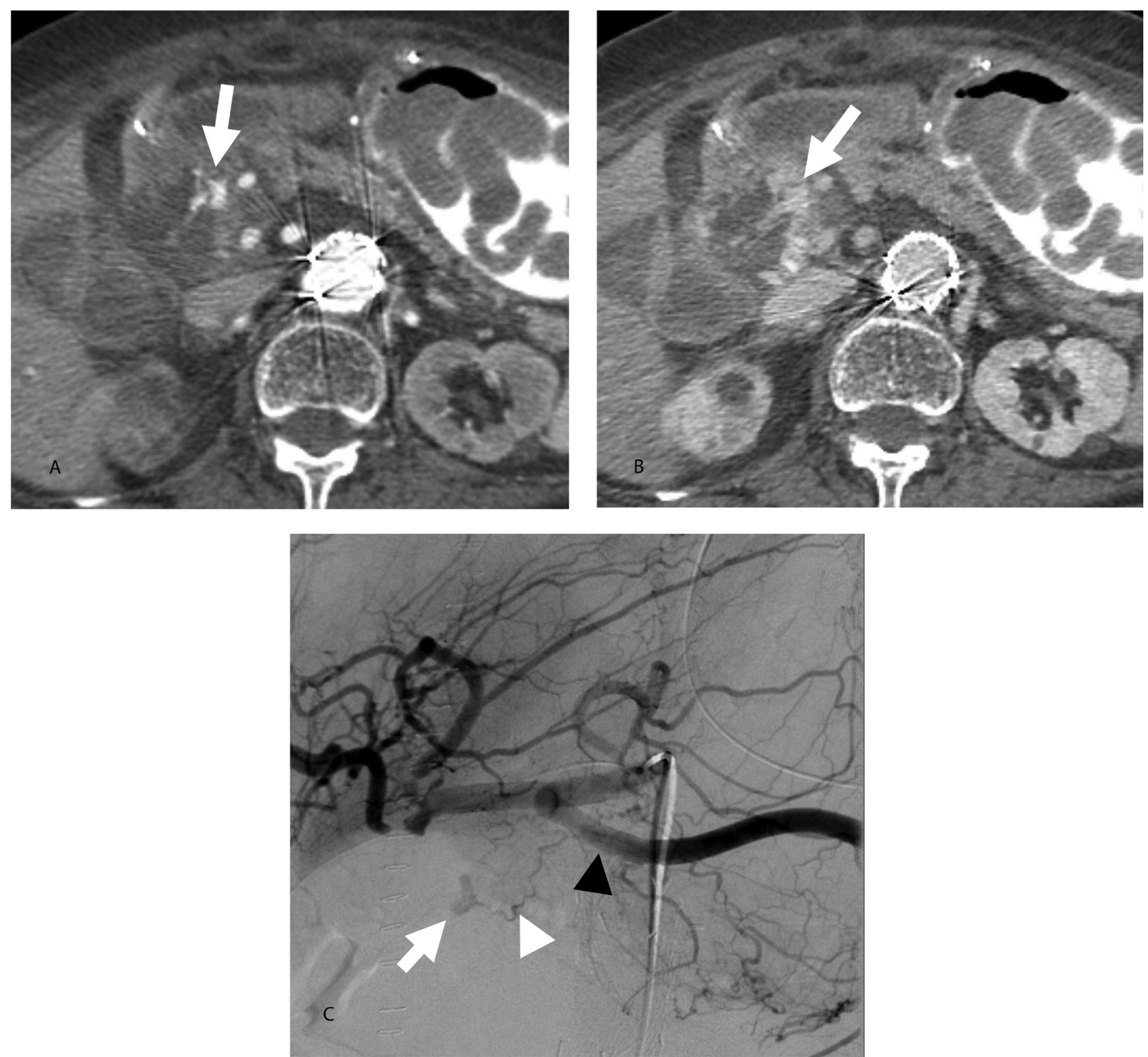

Fig. 8 An 83-year-old female with tachycardia and abdominal distention post Whipple surgery. Axial arterial phase postcontrast CT image (A) shows active extravasation of contrast (arrow) with irregular hyperdense puddles within the wall and lumen of the jejunum at the pancreaticojenostomy (PJ), with increasing corresponding hyperdensity/contrast collection (arrow) on the venous postcontrast phase CT (B). Conventional fluoroscopic celiac angiogram image (C) shows corresponding irregular active contrast extravasation due to bleeding (long arrow) from a tiny branch (short arrow) of the splenic artery (black arrow). Bleeding was stopped following immediate embolization.

indicative, particularly if the collection is related to the pancreatic duct or anastomotic suture line. ${ }^{47}$ Development of a pancreatic fistula is also linked to other complications including pancreatitis, abscess, and sepsis, with significant $(20-40 \%)$ mortality. ${ }^{44,46}$ Factors like gender (male), pancreatic duct-jejunum double-layer mucosa-to-mucosa PJ anastomosis, pancreatic duct diameter $\leq 3 \mathrm{~mm}$, degree of pancreatic fibrosis and soft pancreatic parenchyma are associated with high risk of pancreatic fistula after PD. ${ }^{47}$ Presence of congenital pancreatic anomalies, for example, circumportal (annular pancreas), can also lead to increased incidence of postoperative pancreatic fistula and a special attention should be paid to look for pancreatic anomalies during surgery/pancreatectomy. Preoperative imaging is also the key for its early identification. Finding of pancreatic parenchyma encircling the PV/SMV suggests the presence of annual pancreas, and helps alert the surgeon to anticipate the aberrant surgical field and be careful to avoid the associated complications..$^{48}$

Management of pancreatic fistula consists of parenteral nutrition, empirical antibiotics, percutaneous drainage, and octreotide. Unless severe anastomotic dehiscence is strongly suspected, surgical repair is rarely attempted..$^{49}$

5. PV thrombosis (PVT) and SMV thrombosis (SMVT): PVT/ SMVT is rare, but serious complication of Whipple procedure (incidence $\sim 17 \%$ ), and needs prompt diagnosis 


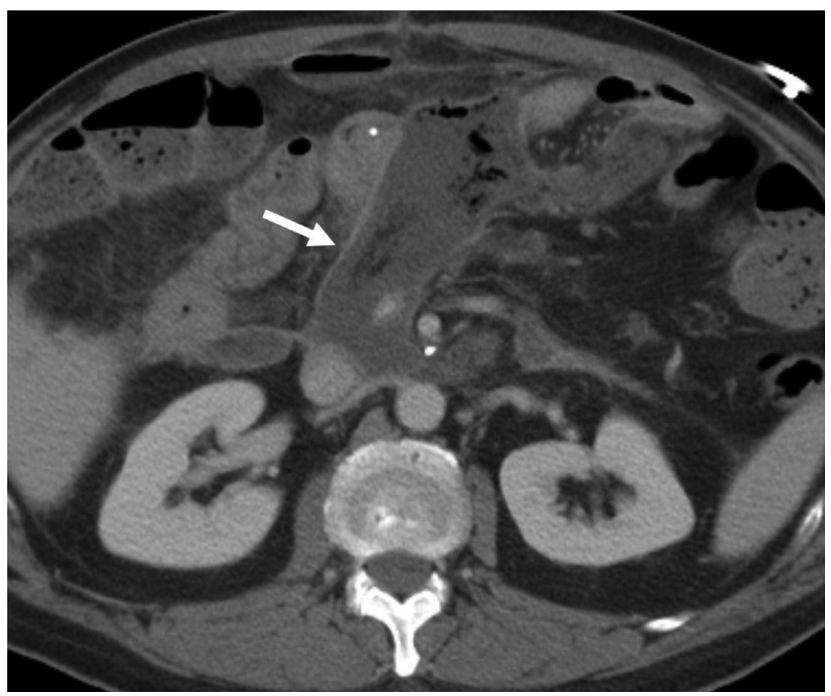

Fig. 9 A 52-year-old man who was 20 days status post Whipple surgery for pancreatic head cancer, underwent contrast-enhanced CT (CECT) for assessment of surgical bed fluid collections. Persistent complicated rimenhancing fluid collection (arrow) was seen in the surgical bed with foci of gas related to catheterization. Drainage fluid was positive for amylase, suspicious for pancreatic fistula. Patient required long-term drainage catheter, and was treated conservatively with gradual improvement. Delayed gastric emptying (not shown) also complicated postoperative course.

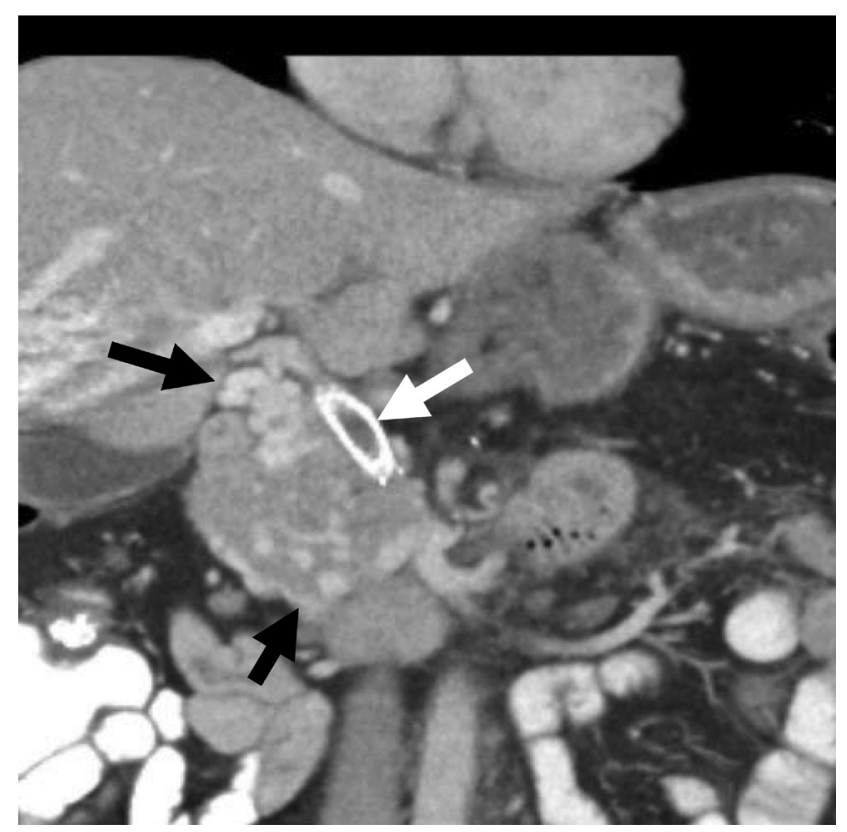

Fig. 10 A 40-year-old woman with status post portal vein stenting due to complication of portal vein stenosis with postprandial pain following distal pancreatectomy for mucinous cystic neoplasm. Coronal postcontrast CT 9 months after the stent placement, shows occlusive thrombosis of the stented main portal vein (white arrow), associated with multiple periportal and peripancreatic venous collaterals (black arrows).

and aggressive management..$^{50}$ PVT/SMVT can be disastrous with risk of intestinal ischemia/necrosis with sepsis, multiple organ dysfunction syndrome (MODS), and multiple organ failure (MOF), which can be fatal..$^{51}$ The two most important risk factors are long operative times and use of prosthetic grafts for reconstruction. Doppler ultrasound is used as first-line assessment in acute clinical setting, showing lack of blood flow or venous waveforms in the corresponding veins. On CT or MRI, perfusion abnormalities may be identified on the arterial phase associated with filling defects on the portal venous phase. However, radiological diagnosis may not be that obvious and sometimes missed, especially if the reader focuses only on axial images. Coronal images ( - Fig. 10) are often important for accurate diagnosis and both veins should be carefully evaluated in the coronal plane to search for short-segment filling defects that may be difficult to visualize on the axial images. ${ }^{52,53}$ Patients are treated with systemic anticoagulation, but surgical thrombectomy may be an alternative in the acute setting. ${ }^{50}$

6. Postoperative pancreatitis: Because of the expected inflammatory changes and fat stranding in the surgical bed after PD, diagnosis of mild postoperative pancreatitis is not easy. Moreover, surgical manipulation can also elevate the levels of amylase and lipase making it even difficult to confirm the diagnosis. ${ }^{54}$ MDCT can detect severe cases as the peripancreatic inflammation, stranding, and fluid is more evident in those cases. Severe postoperative pancreatitis is reported in up to $30 \%$ of cases. ${ }^{54}$

7. Delayed gastric emptying: Incidence of delayed gastric emptying varies and may be 4 to $59 \%$ based on the criteria applied. Clinically, it is diagnosed based on the persistence of nasogastric tube (NGT) after surgery, reinsertion of postoperative NGT, or delay in starting regular diet. ${ }^{55}$ In most cases, delayed gastric emptying is an indication of another underlying complication, for example, abscess, fistula, and hemorrhage. Barium and nuclear medicine studies can help confirm the diagnosis of delayed gastric emptying. ${ }^{56}$

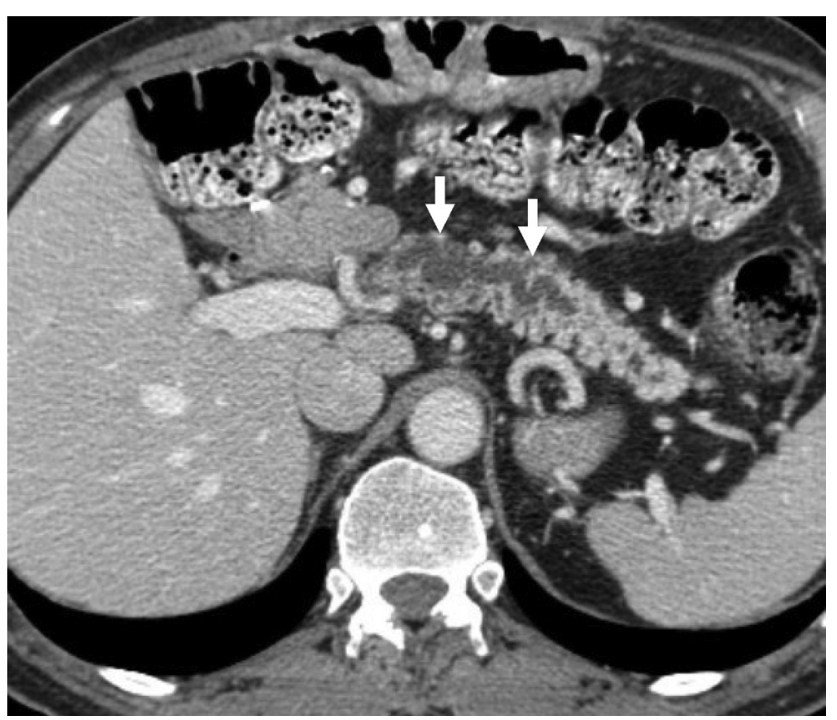

Fig. 11 A 54-year-old man who was 1-year status post Whipple surgery for pancreatic head cancer, underwent contrast-enhanced CT (CECT) for recurrent abdominal pain. CECT revealed moderately dilated (arrows) pancreatic duct in the remnant pancreas suspicious for stricture at the pancreaticojejunostomy. Patient required a redo pancreaticojejunostomy for treatment. 


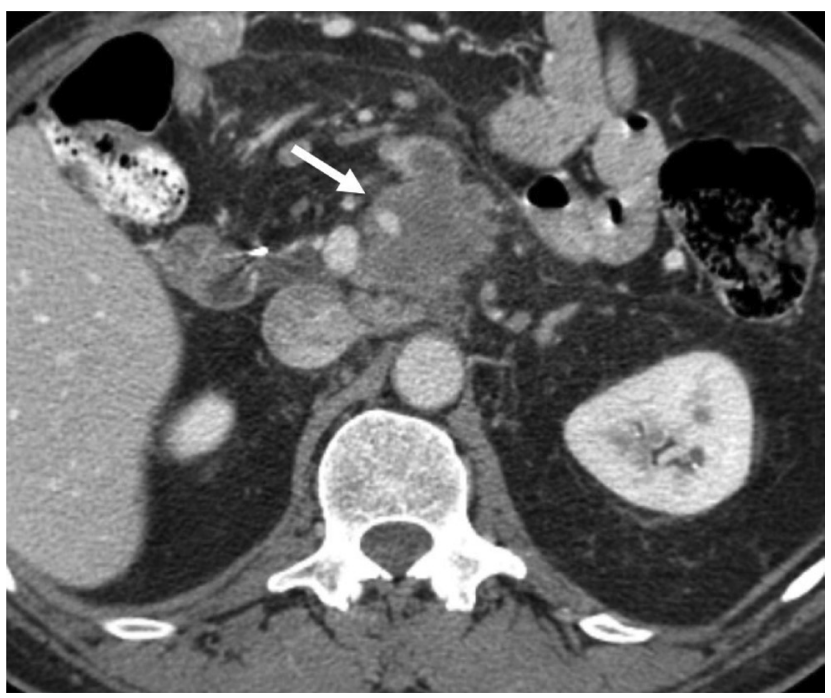

Fig. 12 A 55-year-old man who was status post Whipple surgery for pancreatic head cancer 2 years ago, presented with crampy abdominal pain and steatorrhea, which did not respond to pancreatic enzyme supplements. Contrast-enhanced CT (CECT) revealed a heterogeneously enhancing mass (arrow) in the mesenteric root encasing the superior mesenteric artery suspicious for recurrent malignancy. This was proven on biopsy.

8. Strictures: These are the most common delayed complications of PD, and mostly occur at both the PJ or HJ anastomoses with incidence of $4.6 \%$ and $8.2 \%$, respectively, at 5 years. ${ }^{57.58}$ Patients of $\mathrm{HJ}$ strictures usually presents with jaundice and cholangitis, while PJ strictures commonly manifests with abdominal pain, diarrhea, steatorrhea, pancreatic insufficiency, and recurrent pancreatitis with pseudocysts on imaging ${ }^{56}$. Contrast enhanced-CT plays a vital role in diagnosing anastomotic strictures

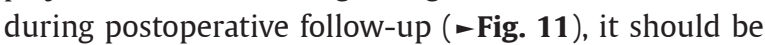
suspected if there is change in the size of intrahepatic bile ducts or the pancreatic duct, which warrants further evaluation. ${ }^{59,60}$ MRCP has good specificity in the diagnosis of strictures, but it is not that sensitive. ${ }^{59,60}$ Secretin induced MRCP is shown to detect the functional and subtle PJ anastomotic strictures compared with EUS and ERCP with accurate detection of pancreatic duct and anastomotic abnormalities while sparing patients the need for an invasive procedure. ${ }^{61}$

Mechanical obstruction of the bowel loops by edema, early or late postoperative adhesions and anastomotic narrowing/strictures, or, rarely, anastomotic ulceration may lead to what is called "afferent loop syndrome/obstruction" (ALS). The afferent loop refers to the duodenojejunal loop proximal to the gastrojejunal anastomosis. ${ }^{62}$ Its obstruction presents with abdominal pain and vomiting. On imaging, it appears as dilated fluid-filled tubular or C-shaped bowel (afferent limb/ loop) in the right upper quadrant or crossing the midline with transition in the region of anastomosis. This often requires surgery to prevent further complications. ${ }^{63,64}$ Nonanastomotic bowel obstruction can also result from adhesions or internal hernia, as seen following other abdominal surgeries.
9. Hepatic infarction: Due to the fact that liver has dual blood supply (from HA and PV), hepatic infarction is a very rare complication. It may occur because of the specific vulnerability of patients exposed to the Whipple procedure, for example, long-term clamp, HA injury or CA compression syndrome, HA thrombosis, or PVT. Other risk factors include hypotension, sepsis, preexisting atherosclerotic disease, fibromuscular dysplasia, or mesenteric vasculitis. ${ }^{65,66}$ It is seen as peripheral wedgeshaped area of decreased enhancement in the liver. Traversing vessels and lack of mass effect distinguishes this from a hepatic mass. ${ }^{67}$

10. Local tumor recurrence in the surgical bed: Most of the patients with disease recurrence, usually present with distant metastatic disease, with only $~ 30 \%$ present with an isolated surgical bed recurrence. ${ }^{68,69}$ The median time of recurrence is around 20 months after initial treatment. ${ }^{68}$ Presence of positive surgical margin is by far the most important risk factor for recurrence. ${ }^{69}$ MDCT is the modality of choice for diagnosis of local recurrent mass ( - Fig. 12) with an accuracy of $94 \%{ }^{5}$ Correlation with elevated carbohydrate antigen (CA) 19-9 levels is useful in distinguishing the recurrence from inflammatory stranding. ${ }^{70}$

\section{Conclusion}

Surgical intervention remains the main treatment option for both the neoplastic and intractable inflammatory pancreatic diseases, despite the development of various medical and minimally invasive treatment approaches for pancreatic disease. Radiologists are required to be familiar with the normal or expected postoperative imaging findings following different types of pancreatic surgeries, to timely detect the postoperative complications or tumor recurrence.

\section{Conflict of Interest}

None declared.

\section{References}

1 Morgan DE. Imaging after pancreatic surgery. Radiol Clin North Am 2012;50(3):529-545

2 Cameron JL. Long-term survival following pancreaticoduodenectomy for adenocarcinoma of the head of the pancreas. Surg Clin North Am 1995;75(5):939-951

3 Johnson PT, Curry CA, Urban BA, Fishman EK. Spiral CT following the Whipple procedure: distinguishing normal postoperative findings from complications. J Comput Assist Tomogr 2002;26(6):956-961

4 Mortelé KJ, Lemmerling M, de Hemptinne B, De Vos M, De Bock G, Kunnen M. Postoperative findings following the Whipple procedure: determination of prevalence and morphologic abdominal CT features. Eur Radiol 2000;10(1):123-128

5 Scialpi M, Scaglione M, Volterrani L, et al. Imaging evaluation of post pancreatic surgery. Eur J Radiol 2005;53(3):417-424

6 Wolfgang CL, Corl F, Johnson PT, et al. Pancreatic surgery for the radiologist, 2011: an illustrated review of classic and newer surgical techniques for pancreatic tumor resection. AJR Am J Roentgenol 2011;197(6):1343-1350 
7 Bluemke DA, Fishman EK, Kuhlman J. CT evaluation following Whipple procedure: potential pitfalls in interpretation. J Comput Assist Tomogr 1992;16(5):704-708

8 Standring S, ed. Gray's Anatomy, The Anatomical Basis of Clinical Practice. Amsterdam, the Netherlands: Elsevier; 2006

9 Sim JS, Choi BI, Han JK, et al. Helical CT anatomy of pancreatic arteries. Abdom Imaging 1996;21(6):517-521

10 Kimura W, Hirai I, Yamaguchi H, Wakiguchi S, Murakami G, Kimura Y. Surgical anatomy of arteries running transversely in the pancreas, with special reference to the superior transverse pancreatic artery. Hepatogastroenterology 2004;51(58):973-979

11 Crabo LG, Conley DM, Graney DO, Freeny PC. Venous anatomy of the pancreatic head: normal CT appearance in cadavers and patients. AJR Am J Roentgenol 1993;160(5):1039-1045

12 Michalski CW, Weitz J, Büchler MW. Surgery insight: surgical management of pancreatic cancer. Nat Clin Pract Oncol 2007;4(9):526-535

13 Tamm EP, Silverman PM, Charnsangavej C, Evans DB. Diagnosis, staging, and surveillance of pancreatic cancer. AJR Am J Roentgenol 2003;180(5):1311-1323

14 Whipple AO. The rationale of radical surgery for cancer of the pancreas and ampullary region. Ann Surg 1941;114(4):612-615

15 Howard JM. Development and progress in resective surgery for pancreatic cancer. World J Surg 1999;23(9):901-906

16 Warshaw AL, Thayer SP. Pancreaticoduodenectomy. J Gastrointest Surg 2004;8(6):733-741

17 Romano G, Agrusa A, Galia M, et al. Whipple's pancreaticoduodenectomy: surgical technique and perioperative clinical outcomes in a single center. Int J Surg 2015;21(Suppl 1) :S68-S71

18 Cheng Y, Briarava M, Lai M, et al. Pancreaticojejunostomy versus pancreaticogastrostomy reconstruction for the prevention of postoperative pancreatic fistula following pancreaticoduodenectomy. Cochrane Database Syst Rev 2017;9:CD012257

19 Traverso LW, Longmire WP Jr. Preservation of the pylorus in pancreaticoduodenectomy. Surg Gynecol Obstet 1978;146(6):959-962

20 Goh BK, Tan YM, Chung YF, et al. Critical appraisal of 232 consecutive distal pancreatectomies with emphasis on risk factors, outcome, and management of the postoperative pancreatic fistula: a 21-year experience at a single institution. Arch Surg 2008;143(10):956-965

21 Tieftrunk E, Demir IE, Schorn S, et al. Pancreatic stump closure techniques and pancreatic fistula formation after distal pancreatectomy: meta-analysis and single-center experience. PLoS One 2018;13(6):e0197553

22 Fingerhut A, Uranues S, Khatkov I, Boni L. Laparoscopic distal pancreatectomy: better than open? Transl Gastroenterol Hepatol 2018;3:49

23 Lillemoe KD, Kaushal S, Cameron JL, Sohn TA, Pitt HA, Yeo CJ. Distal pancreatectomy: indications and outcomes in 235 patients. Ann Surg 1999;229(5):693-698, discussion 698-700

24 Hamad A, Novak S, Hogg ME. Robotic central pancreatectomy. J Vis Surg 2017;3:94

25 Celis Zapata J, Berrospi Espinoza F, Ruiz Figueroa E, Payet Meza E, Chavez Passiuri I, Young Tabusso F. Central pancreatectomy. Indications and perisurgical results of a pancreatic tissue conservation technique [in Spanish]. Rev Gastroenterol Peru 2005;25(4):349-355

26 Adham M, Giunippero A, Hervieu V, Courbière M, Partensky C. Central pancreatectomy: single-center experience of 50 cases. Arch Surg 2008;143(2):175-180, discussion 180-181
27 Christein JD, Smoot RL, Farnell MB. Central pancreatectomy: a technique for the resection of pancreatic neck lesions. Arch Surg 2006;141(3):293-299

28 van Heerden JA, Mcllrath DC, Ilstrup DM, Weiland LH. Total pancreatectomy for ductal adenocarcinoma of the pancreas: an update. World J Surg 1988;12(5):658-662

29 Casadei R, Monari F, Buscemi S, et al. Total pancreatectomy: indications, operative technique, and results: a single centre experience and review of literature. Updates Surg 2010;62(1):41-46

30 Heiken JP, Balfe DM, Picus D, Scharp DW. Radical pancreatectomy: postoperative evaluation by CT. Radiology 1984;153(1):211-215

31 Zakaria HM, Stauffer JA, Raimondo M, Woodward TA, Wallace $\mathrm{MB}$, Asbun HJ. Total pancreatectomy: short- and long-term outcomes at a high-volume pancreas center. World J Gastrointest Surg 2016;8(9):634-642

32 Seo JW, Hwang HK, Lee M, et al. Normal postoperative computed tomography findings after a variety of pancreatic surgeries. Korean J Radiol 2017;18(2):299-308

33 Yamauchi FI, Ortega CD, Blasbalg R, Rocha MS, Jukemura J, Cerri GG. Multidetector CT evaluation of the postoperative pancreas. Radiographics 2012;32(3):743-764

34 Raman SP, Horton KM, Cameron JL, Fishman EK. CT after pancreaticoduodenectomy: spectrum of normal findings and complications. AJR Am J Roentgenol 2013;201(1):2-13

35 Chincarini M, Zamboni GA, Pozzi Mucelli R. Major pancreatic resections: normal postoperative findings and complications. Insights Imaging 2018;9(2):173-187

36 Castellanos JA, Merchant NB. Intensity of follow-up after pancreatic cancer resection. Ann Surg Oncol 2014;21(3):747-751

37 Schulick RD. Complications after pancreaticoduodenectomy: intraabdominal abscess. J Hepatobiliary Pancreat Surg 2008;15(3):252-256

38 Grobmyer SR, Kooby D, Blumgart LH, Hochwald SN. Novel pancreaticojejunostomy with a low rate of anastomotic failure-related complications. J Am Coll Surg 2010;210(1):54-59

39 Benzoni E, Zompicchiatti A, Saccomano E, et al. Postoperative complications linked to pancreaticoduodenectomy. An analysis of pancreatic stump management. J Gastrointestin Liver Dis 2008;17(1):43-47

40 Limongelli $\mathrm{P}$, Khorsandi SE, Pai M, et al. Management of delayed postoperative hemorrhage after pancreaticoduodenectomy: a meta-analysis. Arch Surg 2008;143(10): 1001-1007, discussion 1007

41 Kim BS, Li BT, Engel A, et al. Diagnosis of gastrointestinal bleeding: a practical guide for clinicians. World J Gastrointest Pathophysiol 2014;5(4):467-478

42 Walker TG, Salazar GM, Waltman AC. Angiographic evaluation and management of acute gastrointestinal hemorrhage. World J Gastroenterol 2012;18(11):1191-1201

43 Balachandran P, Sikora SS, Raghavendra Rao RV, Kumar A, Saxena R, Kapoor VK. Haemorrhagic complications of pancreaticoduodenectomy. ANZ J Surg 2004;74(11):945-950

44 Büchler MW, Friess H, Wagner M, Kulli C, Wagener V, Z'Graggen K. Pancreatic fistula after pancreatic head resection. Br J Surg 2000;87(7):883-889

45 Hashimoto M, Koga M, Ishiyama K, et al. CT features of pancreatic fistula after pancreaticoduodenectomy. AJR Am J Roentgenol 2007;188(4):W323-7

46 Machado NO. Pancreatic fistula after pancreatectomy: definitions, risk factors, preventive measures, and management-review. Int J Surg Oncol 2012;2012:602478

47 Hu BY, Wan T, Zhang WZ, Dong JH. Risk factors for postoperative pancreatic fistula: analysis of 539 successive 
cases of pancreaticoduodenectomy. World J Gastroenterol 2016;22(34):7797-7805

48 Ohtsuka T, Mori Y, Ishigami K, et al. Clinical significance of circumportal pancreas, a rare congenital anomaly, in pancreatectomy. Am J Surg 2017;214(2):267-272

49 You DD, Paik KY, Park IY, Yoo YK. Randomized controlled study of the effect of octreotide on pancreatic exocrine secretion and pancreatic fistula after pancreatoduodenectomy. Asian J Surg 2019;42(2):458-463

50 Smoot RL, Christein JD, Farnell MB. Durability of portal venous reconstruction following resection during pancreaticoduodenectomy. J Gastrointest Surg 2006;10(10):1371-1375

51 Zyromski NJ, Howard TJ. Acute superior mesenteric-portal vein thrombosis after pancreaticoduodenectomy: treatment by operative thrombectomy. Surgery 2008;143(4):566-567

52 Sze DY, O’Sullivan GJ, Johnson DL, Dake MD. Mesenteric and portal venous thrombosis treated by transjugular mechanical thrombolysis. AJR Am J Roentgenol 2000;175(3):732-734

53 Ouaïssi M, Sielezneff I, Pirro N, et al. Therapeutic anticoagulant does not modify thromboses rate vein after venous reconstruction following pancreaticoduodenectomy. Gastroenterol Res Pract 2008;2008:896320

54 Räty S, Sand J, Lantto E, Nordback I. Postoperative acute pancreatitis as a major determinant of postoperative delayed gastric emptying after pancreaticoduodenectomy. J Gastrointest Surg 2006;10(8):1131-1139

55 Sakamoto Y, Yamamoto Y, Hata S, et al. Analysis of risk factors for delayed gastric emptying (DGE) after 387 pancreaticoduodenectomies with usage of 70 stapled reconstructions. J Gastrointest Surg 2011;15(10):1789-1797

56 Mucci-Hennekinne S, Brachet D, Clouston H, Pessaux P, Hamy A, Arnaud JP. Management of a stenotic pancreatico-digestive tract anastomosis following pancreatoduodenectomy. J Hepatobiliary Pancreat Surg 2007;14(5):514-517

57 Reid-Lombardo KM, Ramos-De la Medina A, Thomsen K Harmsen WS, Farnell MB. Long-term anastomotic complications after pancreaticoduodenectomy for benign diseases. J Gastrointest Surg 2007;11(12):1704-1711

58 House MG, Cameron JL, Schulick RD, et al. Incidence and outcome of biliary strictures after pancreaticoduodenectomy. Ann Surg 2006;243(5):571-576, discussion 576-578
59 Morgan KA, Fontenot BB, Harvey NR, Adams DB. Revision of anastomotic stenosis after pancreatic head resection for chronic pancreatitis: is it futile? HPB (Oxford) 2010;12(3):211-216

60 Nordback I, Parviainen M, Piironen A, Räty S, Sand J. Obstructed pancreaticojejunostomy partly explains exocrine insufficiency after pancreatic head resection. Scand J Gastroenterol 2007;42(2):263-270

61 Boraschi P, Donati F, Cervelli R, Pacciardi F. Secretin-stimulated MR cholangiopancreatography: spectrum of findings in pancreatic diseases. Insights Imaging 2016;7(6):819-829

62 Nageswaran H, Belgaumkar A, Kumar R, et al. Acute afferent loop syndrome in the early postoperative period following pancreaticoduodenectomy. Ann R Coll Surg Engl 2015;97(5):349-353

63 Pannala R, Brandabur JJ, Gan SI, et al. Afferent limb syndrome and delayed GI problems after pancreaticoduodenectomy for pancreatic cancer: single-center, 14-year experience. Gastrointest Endosc 2011;74(2):295-302

64 Juan Y-H, Yu C-Y, Hsu H-H, et al. Using multidetector-row CT for the diagnosis of afferent loop syndrome following gastroenterostomy reconstruction. Yonsei Med J 2011;52(4):574-580

65 Lev-Toaff AS, Friedman AC, Cohen LM, Radecki PD, Caroline DF. Hepatic infarcts: new observations by CT and sonography. AJR Am J Roentgenol 1987;149(1):87-90

66 Miura F, Asano T, Amano H, et al. Eleven cases of postoperative hepatic infarction following pancreato-biliary surgery. J Gastrointest Surg 2010;14(2):352-358

67 Giovine S, Pinto A, Crispano S, Lassandro F, Romano L. Retrospective study of 23 cases of hepatic infarction: CT findings and pathological correlations. Radiol Med (Torino) 2006;111(1):11-21

68 Roeder F. Neoadjuvant radiotherapeutic strategies in pancreatic cancer. World J Gastrointest Oncol 2016;8(2):186-197

69 Showalter TN, Rao AS, Rani Anne P, et al. Does intraoperative radiation therapy improve local tumor control in patients undergoing pancreaticoduodenectomy for pancreatic adenocarcinoma? A propensity score analysis. Ann Surg Oncol 2009;16(8):2116-2122

70 Heye T, Zausig N, Klauss M, et al. CT diagnosis of recurrence after pancreatic cancer: is there a pattern? World J Gastroenterol 2011;17(9):1126-1134 